\title{
Macrophytography of Cultivated Liriopogons and Genera Delineation
}

\author{
Paul R. Fantz ${ }^{1,2}$
}

AdDitional INDEX words. Liviope, Ophiopogon, Convallariaceae, Haemodoraceae, Liliaceae, Ophiopogonaceae, Ruscaceae, morphology, ground covers, aztec grass, lilyturf, mondo grass, monkey grass, snakesbeard

SumMARY. Liriopogons (Liviope Lour. spp. and Ophiopogon Ker-Gawl. spp.) are versatile landscape plants with a complexity of taxonomic problems, including the question of whether they are segregate genera or only one genus.

Macrophytography (descriptive terminology of morphology) of the liriopogons is described with commentary on patterns of variation and reliable characters for segregation. Liriopogons were found to include two valid genera, delineated and described, and two imposters marketed as liriopogons. Liviope species bear spreading to upright rotate flowers with zygomorphic stamens, of which the filaments are sigmoid, the anthers oblong and poricidal dehiscent, and the style is incurved-falcate. Ophiopogon species bear nodding campanulate flowers with actinomorphic stamens, of which the filaments are subsessile and straight, the anthers sagittate and longitudinally dehiscent, and the style is straight. The imposters are nonvalid liriopogons, and include species of sedges and grasses misidentified as liriopogons. Included are a key to delineation of taxa and a table of taxonomic terminology used in this study for describing liriopogon taxa.

L iriopogons are versatile landscape plants that are becoming increasingly important in the nursery and landscape industries (Adams, 1989). Liriopogons are commonly known as 'aztec grass', 'lilyturfs', 'mondo grass', 'monkey grass', or infrequently as 'snakebeards' in the green industry trade (Fantz, 1993). A complexity of taxonomic problems were reported that needed to be resolved in cultivated liriopogons (Fantz, 1993). How can one segregate species and cultivars? Are liriopogons members of one genus or two genera (Ophiopogon and Liriope)? The latter question needs to be resolved first to begin addressing the previous question.

Salary and research support provided in part by the North Carolina Agricultural Research Service (NCARS), Raleigh, NC 27695-7643. Additional funds in support of research provided by Taylor's Nursery, Inc. (Raleigh, NC) and publication funds provided by the North Carolina Association of Nurserymen, Inc. (Raleigh, NC).

Thanks go to Paul Lineberger, retired Superintendent, Horticultural Field Laboratory, Raleigh, and his staff for cultural assistance with germplasm collection used in this study, and to those individuals, nurseries, and botanical gardens listed in Table $l$ that donated plants for this research

The use of nursery and trade names in this publication does not imply endorsement by the NCARS of the nurseries or products named nor criticism of similar ones not mentioned.

${ }^{1}$ Department of Horticultural Science, North Carolina State University, Raleigh, NC 27695-7609

${ }^{2}$ Corresponding author. E-mail: paul_fantz@ ncsu.edu.
Liriope and Ophiopogon were united under the genus Ophiopogon (Maximowicz, 1781), as distinguishing features were limited. L.H. Bailey discussed the complex nomenclatural history and was unsure if there were two distinct genera or one genus as treated by botanists in the $1800 \mathrm{~s}$ (Bailey, 1929). However, he did not merge them, but recognized two genera of cultivated liriopogons as Liriope and Mondo (Kaempf.) Adanson (Bailey, 1929). Currently, Ophiopogon is a conserved name recognized internationally over the name Mondo. Modern authors have followed Bailey's treatment of two genera, including the official reference of the American Society for Horticultural Science for correct scientific names (Griffiths, 1994). However, recent molecular research is leading to conclusions that support only one genus, not two (Cutler, 1992; Mcharo et al., 2003; Rudall et al., 2000).

Ophiopogon was placed originally in the Haemodoraceae Arnott (Bentham and Hooker, 1880). Later, the genus was transferred to several families, including Ophiopogonaceae Endl., Liliaceae Juss., Convallariaceae Horan., and currently (Stevens, 2006), Ruscaceae Spreng.

Members of liriopogons are difficult to segregate and identify by many professionals in the nursery and landscape industries. They typically use only a few characters for segregation of species: growth form ("clumper" vs. "runner"), height, leaf length and width, and flower color. These traits are variable when one examines named plants. Hence, common or vernacular names used for these plants typically are associated across generic lines. One needs to clearly define and understand plant characteristics exhibited and their patterns of variation before one can use those characters that are distinct and reliable for distinguishing genera segregation, delineation, and accurate identification of plants used in molecular research projects.

Phytography is the descriptive terminology (morphology) of plants and their component parts for the purpose of providing an accurate and complete vocabulary for descriptions, identification, and classification (Radford et al., 1974). Macrophytography includes structures one can observe with the naked eye, hand lens, or a low-powered microscope $(\times 10$ to $\times 30)$.

A taxonomic program was initiated at North Carolina State University with the objective of a taxonomic revision to include an inventory of cultivated germplasm, quantitative descriptions of taxa, observational notes, nomenclatural comment, documented vouchers, and identification aids (e.g., keys). In the green industry today, there are four distinct genera sold as liriopogons! The objectives herein were to define the phytography, to discuss the morphology of liriopogons and patterns of variation observed, to determine the number of liriopogon genera, and to note those characters that are being used in developing quantitative descriptions of the taxa.

\begin{tabular}{llll}
\hline $\begin{array}{l}\text { Units } \\
\begin{array}{l}\text { To convert U.S. to SI, } \\
\text { multiply by }\end{array}\end{array}$ & U.S. unit & SI unit & $\begin{array}{l}\text { To convert SI to U.S., } \\
\text { multiply by }\end{array}$ \\
\hline 2.54 & inch(es) & $\mathrm{cm}$ & 0.3937 \\
25.4 & inch(es) & $\mathrm{mm}$ & 0.0394
\end{tabular}




\section{Materials and methods}

Germplasm of liriopogons cultivated in the United States were accumulated, grown together from 1990 to 2005 for morphological comparison and observation, and vouchered as described by Fantz (1994). Table 1 summarizes the sources of germplasm collections reported (Fantz, 1994), and includes the known original source of origin of some taxa being introduced into the U.S. from China, England, Germany, and Japan. Table 2 summarizes the morphological characters from which data were obtained for each taxon examined. Table 3 provides the phytographic descriptive terminology used by this author and others (Bagust, 1992; Dahlgren and Clifford, 1982; Dahlgren et al., 1985; Harris and Harris, 1994) that follows standard taxonomic references.

\section{Results and discussion}

Results obtained and the following discussion will be presented in five parts. First, phytography of liriopogon morphology and patterns of variation are discussed, organ by organ. Second, characters reliable for genera and species segregation are presented. Third, the number of liriopogon genera are discussed. Fourth, discussion is presented on five common names used for liriopogons in the green industry. And fifth, a key is presented to the cultivated genera that are sold as liriopogons along with generic descriptions of the true liriopogons.

\section{Phytography.}

Liriopogons are herbaceous perennials. Those cultivated in the eastern United States are primarily acaulescent, bearing a basal rosette of grass-like leaves from a subterranean stem. The leafless, flower-bearing scape is the only erect "stem-like" structure. Caulescent members are rare, and typically are not available currently in the commercial green industry.

GrowTH FORM. Most plants are rhizatomous ("runner"), sending out specialized stems (rhizomes) from the caudex of the mother plant just beneath the soil. Rhizomes end in a daughter plant growing upright through the soil and this stem deteriorates with age, breaking off from the mother plant. Strongly rhizatomous plants have elongate rhizomes, leaving open patches between plantlets. These members are typically vigorous growers, becoming aggressive in landscapes, and appearing weedy. Weakly rhizatomous plants have short runners, with daughter plants borne close to the mother plant and their roots intertwining. This growth pattern will form a dense carpet or mound over the ground with age, with original planting sites merging together, providing an attractive ornamental appearance. These plants commonly are cited as stoloniferous in the literature, but stolons are defined historically as specialized horizontal stems that creep along the ground on the soil surface, not beneath it (Harris and Harris, 1994; Radford et al., 1974).

Caespitose plants expand outward radially from the caudex crown of the original plant in dense tufts ("clumper"), forming a mound or cushion on the ground with age. The mound includes the original "mother" plant from which lateral secondary plantlets ("daughter plants") produce new clumps of leaves and scapes. Individual mounds are quite distinguishable after several years of growth. Individual plants are crowded together, thus it is difficult to observe soil patches between them as with rhizatomous plants.

Rarely, one will encounter a nonacaulescent growth form. One species was stoloniferous, bearing several short decumbent stems creeping on the ground with ascending branches. Another species was aboreal with leaf-bearing erect and branching aboveground.

Roots. Roots typically were difficult to voucher, because damage occurring as plantlets were excavated from field plantings. However, vouchers of greenhouse-grown plants in containers provided root data. Most liriopogons produce fibrous roots with threadlike segments of equal thickness $(0.5-2 \mathrm{~mm}$ in diameter). Primary segments are elongated and stramineous (straw-colored, a dull brownish-yellow), and produce scarce secondary rootlets. A few produce secondary and tertiary rootlets. Some primary segments bear occasional tuberoids (nodules), a swollen area that resembles a tuber.

Mularoni and Anderson (1987) reported these nodules as repositories
Table 1. Sources of liriopogon germplasm, including the original origin as cited by the source.

Botanic gardens/arboreta

Brookside Gardens, Wheaton, MD

Busse Gardens, Cokato, MN

Carroll Gardens, Westminster, MD

Duke Botanic Gardens, Durham, NC

Hangzhou Botanical Garden, Hangzhou, China

JC Raulston Arboretum, North Carolina State University, Raleigh, NC

Millpond Plantation, Thomasville, GA

Royal Botanic Garden, Kew, UK

U.S. National Arboretum, Washington, DC

Nurseries/garden centers

Bentley Nursery, Monticello, FL

Kurt Blumel, Inc., Baldwin, MD

Classic Groundcovers, Athens, GA

Coastal Gardens and Nursery, Myrtle Beach, SC

Fowler's Nursery, Raleigh, NC

Evergreen Nursery, Athens, GA

Garden Place, Mentor, OH

Gärtnerischer Pfanzenbau,

Marktheidenfeld, Germany

Greenbrier Farms, Chesapeake, VA

Hines Nursery, Fulchear, TX

Ishiguro Momiji-en, Santa Rosa, CA

Juroku-en, Kasugahara, Japan

Kairyo-en, Kawagochi, Japan

K-Mart, Cary, NC

Louisiana Nursery, Opelousas, LA

Malloy Nursery, Monticello, FL

McDonald Garden Center,

Hampton, VA

Micro Macro International, Windemere, FL

Plant Delights Nursery Inc., Raleigh, NC

Powell Gardens, Princeton, NC

Riegel Plant Company,

Experiment, GA

Shady Oaks Nursery, Waseca, MN

Southern States Nursery,

MacClenny, FL

Spring Hill Nursery, Peoria, IL

Swift Creek Nursery, Clayton, NC

Taylor Nursery, Raleigh, NC

Terra Nova Laboratories, Portland, OR

Thomasville Nurseries,

Thomasville, AL

Tidwell Nursery, Atlanta, GA

Andre Viette Perennials, Fisherville, VA

Wal-Mart, Clearwater, FL

Willis Nursery Company, Ottawa, KS

Windmill Farms, Sebring, FL

Individuals

Paul Aden, Long Island, NY

Leo Ammon, Bosman, MD

Tony Avent, Raleigh, NC

Edith Eddleman, Durham, NC

Richard Hartledge, Raleigh, NC

Paul Jones, Durham, NC

Clarence Landis, Spanish Fort, AL

Alex Summers, Bridgeville, DE 
Table 2. Morphological characters examined for determining the diagnostic features of liriopogons and segregating taxa. Measurements were obtained in metric units $(1 \mathrm{~cm}=0.3937 \mathrm{inch}, 1 \mathrm{~mm}=0.0394$ inch $)$.

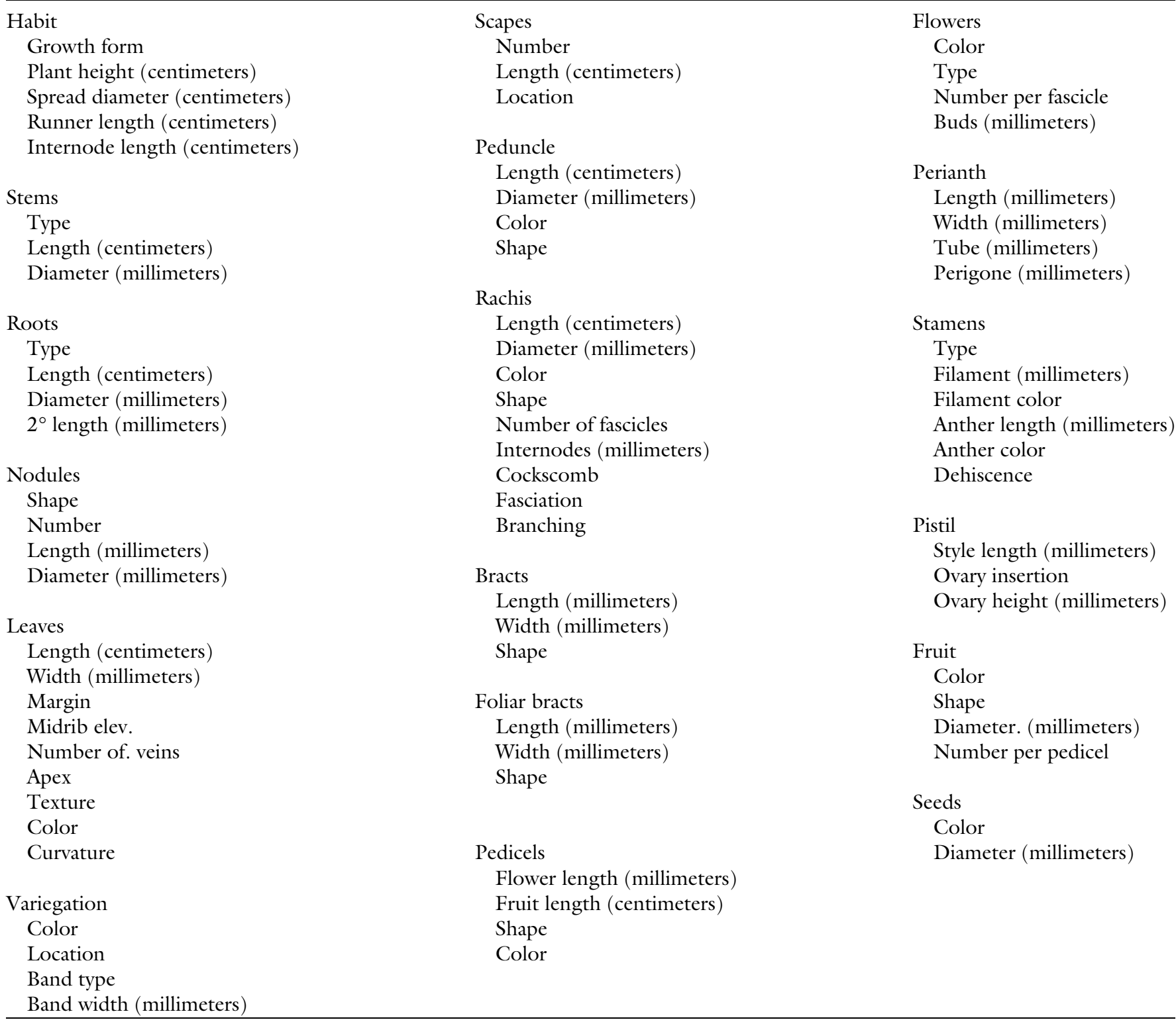

(or storage organs) of a major energy source accumulated over a period of time, and erroneously called a "tuber root." A few members did produce a thickened fleshy root $(2-4 \mathrm{~mm}$ in diameter). Primary segments were elongated, dull whitish, and lacked smaller rootlets.

STEMS. Liriopogons exhibit several stem types. The thickened, subterranean, woody-like caudex is much longer than wide, seemingly devoid of leaves, with inconspicuous nodes. Caudexes are oriented vertically to oblique within the soil. New shoots are produced from lateral buds in the upper lateral portion (crown) of the caudex that quickly bend and grow upward with leaves attached basally. The lower portion of the caudex produces roots that grow outward and down. Vouchering of caudexes in older plants became difficult because of their thickness, which required a spade, knife, or axe to slice through. Pulling up daughter plants often resulted in the younger shoot breaking off from the mother plant.

Most members produce elongate, narrowly cylindrical rhizomes with prominent nodes bearing sessile, clasping, appressed, ascending, imbricated, oblong-deltoidal leaves. New plantlets are produced at the rhizome's tip with grass-like leaves growing upward and fibrous roots growing downward. Rhizomes grow laterally, away from the mother plant just below the soil, often becoming intertwined with other underground rhizomes in the colony as well as with their roots. Rhizomes often break apart when one digs up a plant, as they deteriorate with age. Rare stem types include decumbent stems laying along the ground surface and erect stems that have sparse branching.

LeAves. Liriopogon leaves are evergreen, simple, sessile, distichate, basically linear with a gradual tapering toward the apex, and a less prominent taper toward the base. The margins and some veins produce microscopic 
Table 3. Terminology used in describing the morphology of liriopogons. Measurements used are in metric units $(1 \mathrm{~mm}=$ 0.0394 inches) and standard taxonomic format ( $x-y$ is common measurement range).

\section{Characteristics and definitions}

General terms

Abaxial: lower surface, the side away from the axis.

Acuminate: a prolonged pointed apex, tapering concave curved.

Acute: a pointed apex, tapering straight.

Adaxial: upper surface, the side toward the axis.

Arboreal: stems above ground are erect.

Auricle: small, ear-shaped basal appendage.

Bib: a daughter plant with a few leaves; trade marketing term for sale of individual, daughter, liriopogon plants.

Complicate: folded.

Decumbent: prostrate stem creeping along the surface of the ground.

Glabrous: lacking hairs; glabrate is nearly hairless.

Liriopogon: general term applied to grass-like plants of the genera Liriope and Ophiopogon.

Naviculate: surface bears a keel like a boat.

Phytography: general term for descriptive terminology (morphology) of plants and their component parts.

Pubescent: hairs present.

Sessile: stalkless.

Taxon: a recognizable taxonomic entity with rank not designated, such as a genus, species or cultivar

Translucent: almost transparent structure.

Growth forms

Acaulescent: plants bear a basal rosette of leaves from a subterranean stem (stemless aboveground).

Arboreal: plants bear erect stems above the ground.

Caespitose: plants expand outward radially from crown of subterranean stem in dense tufts forming a mound or cushion on the ground.

Decumbent: plants bear several short stems reclining on the ground with apex and lateral branches erect.

Rhizomatous: plant bears a subterranean stem (caudex) with propagative shoots (rhizomes) sent out that culminate in a daughter plant; often cited as stoloniferous in literature.

Stoloniferous: plant bears a decumbent creeping stem along the ground surface that produces a daughter plant at its tip. Roots

Fibrous: numerous, filamentous (threadlike) roots, $0.5-2 \mathrm{~mm}$ diameter

Fleshy: roots few, thickened, $2-4 \mathrm{~mm}$ diameter

Tuberoids (nodules): swollen segment areas of roots that resemble a tuber.

Stems

Caudex: a short, thickened, vertical, perennial, subterranean stem with daughter plants produced laterally from the caudex.

Rhizome: thickened, subterranean, woody-like stem with inconspicuous nodes, leaves appressed, inconspicuous, deteriorating quickly leaving veins.

Leaves

Appressed: leaves lay flat against stems (on stolons).

Broad leaf: leaves typically 7-13 mm wide.

Clasping leaf: base of the blade wraps around the stem.

Deltoid: leaves are triangular-shaped.

Distichous: leaves are two-ranked along the stem.

Imbricate leaves: leaves overlap each other.

Medium leaf: leaves are typically $5-8 \mathrm{~mm}$ wide.

Mini leaf: leaves typically 3-5 $\mathrm{mm}$ wide.

Narrow leaf: leaves typically $1-3 \mathrm{~mm}$ wide.

Petiolate: leaf blade bears a stalk.

Pliable leaf: leaves easily bent or folded upon itself by man, exhibiting minimal damage.

Rigid leaf: leaves thick-textured, resist bending or folding upon itself by man, and typically tear at folding point.

Wide leaf: leaves are typically $12-23 \mathrm{~mm}$ wide.

Transverse variegated leaf: leaves bear transverse yellowish zones deficient in chlorophyll.

Tristichate: leaves three-ranked on stem.

Variegated leaf: leaves bear longitudinal bands the length of the leaf deficient in chlorophyll and appearing yellow to greenish-yellow to cream to silvery.

Inflorescence

Bract: modified leaf-like structure subtending a flower, borne at base of pedicel.

Branched rachis: rachis branching above, appearing panicle-like; panicle of dichasia.

Cockscomb: general term to a rachis expanding laterally and flattening near the apex.

(Continued on next page) 
Table 3. (Continued) Terminology used in describing the morphology of liriopogons. Measurements used are in metric units ( $1 \mathrm{~mm}=\mathbf{0 . 0 3 9 4}$ inches) and standard taxonomic format ( $\mathrm{x}-\mathrm{y}$ is common measurement range).

\section{Characteristics and definitions}

Congested fascicles: fascicles borne close together with short rachis internodes.

Cymose: reference to a determinate inflorescence that is a compound dichasia or cyme.

Dichasium: type of determinate inflorescence that produces three flowers, the terminal flower opening first.

Fasciation: general term referring to a cockscomb bearing two to several axes bearing flowers from the cockscomb apex.

Fascicle: clusters of flowers or fruit borne laterally from the rachis.

Foliar bract: elongated, leaf-like bract, borne early in season only at the lowest fascicles.

Inflorescence: a flowering branch; also used herein for a fruiting branch.

Loose fascicles: fascicles spaced apart with long rachis internodes, particularly at lower to middle rachis nodes.

Pedicel: stalk of the flower or fruit, measured from the node to the flower base.

Peduncle: stalk of the inflorescence, measured from the base to the node bearing the first buds, flower or fruit.

Plano: peduncles that are flattened in cross-section.

Raceme: an elongated axis bearing pedicillate or stalked flowers.

Rachis: term for the portion of the inflorescence axis from which flowers and fruit are borne.

Scape: general term for an inflorescence borne from an acaulescent plant; leafless inflorescence.

Spike: an elongated axis bearing sessile flowers.

Striae: fine raised lines (= veins) on the scape axis.

Terete: peduncles that are nearly round in cross-section.

Flowers

Actinomorphic: radial symmetry.

Androecium: collective term for the stamens.

Anther: pollen sac in a stamen borne at the apex of the filament.

Bud: an undeveloped flower.

Campanulate: bell-shaped flowers.

Carpel: portion (chamber) of a compound pistil formed from one modified leaf; megasporophyll.

Extrose: turned outward, away from the structure; applied to stamen orientation.

Filament: stalk of the stamen.

Gynoecium: collective term for the female reproductive organ (pistil).

Hemiperigynous ovary: subinferior ovary, other floral parts fused basally with ovary and free parts forming whorls around the ovary.

Hypogynous ovary: superior ovary, ovary borne above insertion of other floral parts.

Ovary: expanded basal portion of pistil that bears the ovules; becomes fruit at maturity.

Perianth: general term that includes sepals and petals collectively, the floral envelope.

Perigone: fused perianth tube that narrows abruptly into a prolonged basal projection.

Petals: the inner whorl of the perianth.

Pistil: female reproductive organ of a flower, comprised of a basal ovary, a style, and the terminal stigma.

Rotate: flowers with a short tube, lobes abruptly spreading, appearing star-shaped.

Sepals: the outer whorl of the perianth.

Sigmoid: S-shaped; applied to shape of filament.

Stamen: male reproductive organ in a flower, comprised of a filament and an anther.

Stigma: terminal portion of pistil that is receptive to pollen.

Style: narrow portion of pistil connecting stigma to the ovary.

Suture: the line of dehiscence in the anther.

Zygomorphic: bilateral symmetry.

Fruit

Berry: feshy fruit developing from a single pistil and bearing several seeds.

Capsule: a dry, dehiscent fruit comprised of more than one carpel.

Drupe: a fleshy, indehiscent fruit developing from a single pistil with a stony endocarp surrounding a single seed.

Testa: the seedcoat.

hyaline teeth that are discernable to the touch as one moves their fingers downward toward the base. Leaves superficially resemble leaves of grasses and sedges, hence are referred to in the literature as "grass-like" leaves. One species is unique with a rapid basal reduction in leaf width to exhibit a "petiole," a rare trait in liriopogons.
Liriopogons leaves are glabrous. One can purchase plants labeled as a liriopogon that has leaves distichate and pubescent intermingled with glabrous leaves. These pubescent leaves belong to grasses that germinated from seeds, and grew as weeds in amongst the liriopogons. Rarely, one can purchase plants labeled as a liriopogon with tristichate leaves.
Tristichate leaves belong to sedges that seeded in and outgrew the liriopogon, or a sedge misidentified and marketed as a new liriopogon.

All liriopogons produce a translucent, thin-texture lateral sheath on each side of the leaf at its base. This sheath is wrapped around other leaves and quickly deteriorates and shreds as leaves mature. Commonly, the leaf 
base between the lateral sheaths is scarcely pigmented with chlorophyll, but becomes prominently yellowishorange in a few members.

Leaf veins are parallel, longitudinal, darker green, and thickened, and are asymmetrical in number on either side of the midrib. The midrib is raised minutely on the adaxial surface in some members, impressed in others. The abaxial surface varies in degrees of glaucousness between veins. Species appear to be consistent in the amount of glaucousness, but interpretation is subjective.

Leaf texture is very subjective in interpretation. Most liriopogons have pliable, very thin leaves that grow upward and arch outward, often exhibiting a broad inverted U-shape such that the leaf apex is oriented downward. Arching occurs somewhere between one-third and three-fourth's of the leaf's length. Thicker-textured leaves are erect with little arching near their tips, often exhibiting an inverted $J$-shape such that the apex is oriented laterally. These leaves are rigid, resist bending, and are difficult to fold, tearing at the point of the fold.

Liriopogon leaves are typically medium to dark green on the upper surface, and lighter beneath. Atypical colors are valued ornamentals. Black mondo grass is a liriopogon noted for its very dark reddish-purple to blackish leaves. Some cultivar selections hold the darker color well. Others will produce green foliage on daughter plants after several years of age, then resemble creeping lilyturfs in appearance. Liriope 'Silver Dragon' is noted for its leaves that are nearly all silvery-white, some which bear longitudinal bands of green. Some older selections produce daughter plantlets with all green foliage. Liriope 'Peedee Ingot' is one member prized for its consistent golden-yellow foliage.

Variegated members as ornamentals are valued, lumped together by growers and landscapers under the generic term 'Variegata' or recognized more recently by a number of distinct names. Variegated areas in the leaf commonly occur in longitudinal bands. Some cultivars have bands restricted to the leaf margin, whereas others exhibit longitudinal bands internally within the leaf that alternate with green chlorophyll bands. The number of bands and their widths are variable in some selections, more constant in others. Juvenile variegated leaves are yellow ("golden") to greenish-yellow, fading to cream to off-white ("silvery") with age. The brightness/dullness of the colors can very between cultivars, as well as within a cultivar, depending upon the plant's age and environmental parameters. Horizontal variegated bands are rare, but do occur, and they vary in width and often are irregular in outline (jagged and lightning bolt-like in appearance).

Leaf width can be divided into five artificial categories that can be useful in cultivar descriptions. These are designated as narrow $(1-3 \mathrm{~mm})$, mini $(3-5 \mathrm{~mm})$, medium $(5-8 \mathrm{~mm})$, broad $(7-13 \mathrm{~mm})$, and wide (12-23 $\mathrm{mm}$ ) widths. Leaves produced later in the season are stunted in growth, up to $80 \%$ shorter than the length of other leaves. Liriopogons grow larger over several years and length measurements will increase slightly for several seasons.

INFLORESCENCE. Commonly, the scape is described as a raceme or spike, which is an oversimplification. Liriopogons produce a compound inflorescence consisting of a raceme with the rachis bearing fascicles of dichasia to compound dichasia (cymose). Scapes produced later in the flowering season have shorter peduncles, some remarkably so, because of a shorter time for optimal growth. Some bibs (a trade term for a young, individual daughter plant) take 1 to 4 years to bloom. Some taxa will bloom infrequently, only once or twice in a decade. Generally, older plants will produce more scapes in successive years than younger plants.

Peduncles elongate rapidly and exhibit two types. Terete peduncles are nearly round in cross-section, often weakly compressed laterally, with a strong striate ridge on two sides with several smaller striae between. Diameter is consistent nearly throughout its length. Typically, these peduncles are green (sometimes becoming purplish) as flowering occurs, and become brownish as fruit develop. Plano peduncles are flatter in cross-section, commonly narrow and unpigmented at the base, gradually widening and becoming pigmented toward the apex.

The rachis develops a consistent length range within taxa, early and later in the flowering season. The rachis is erect on the peduncle in some members and slightly to prominently oblique in other members. The rachis decreases in diameter from the base to the apex, green in the juvenile state, and pigmented from the base upward as flowering progresses. Often, the apex is whitish to light pigmented, leading individuals to interpret the darker pigmented flowers (violet) as lighter in hue (bluish-violet or lavender). Typically, the rachis is unbranched, but occasionally, the lower portion will exhibit a lateral branch, a random character occurring within cultivar selections. A compound rachis exhibits a panicle of dichasia, the rachis branching consistently along most its length, lateral lengths shortening upwards, and appearing pyramidal to cone-shaped (e.g., 'Christmas Tree'). Some cultivars exhibit cockscombs, the rachis becoming flattened and broad, which increases the number of fascicles and flower production. This trait is regarded as unique and more ornamental. Fasciation is associated with some cockscombs, the apex producing two to several erect axes bearing flowers. Both of these branching traits are variable each season in the degree of production in a taxon.

Fascicles are arranged spirally on the rachis and vary in number produced. The fascicles are clusters of dichasia along the rachis, producing three flowers per fascicle, the central one opening first, the lateral pair opening later. Compound dichasia produce clusters of three to seven flowers per fascicle. Congested fascicles are crowded close together with short internodes, whereas loose fascicles are separated by longer internodes, particularly in the lower portion of the rachis.

Pedicels are subquadrangular and often pigmented. They may twist, causing flowers to appear nodding. Pedicels are consistent in length with flowers, but elongate to a new consistent length with fruit.

Bracts are borne at the base of the pedicels and are arranged in two series. The outer bract is conspicuous, larger, complicate to naviculate around the pedicel, the apex acute to acuminate, with margins sometimes bearing translucent auricles as observed in the leaves. The inner bract is small, inconspicuous, usually 
perpendicular to the outer bract and pedicel. A foliar bract is very distinctive, elongated, and leaf-like. It is gigantic-sized for bracts, occurring only in the earliest scape(s) of the season, and only from the lowest fascicle(s), reducing quickly in size up the rachis to become a "typical" bract.

Flowers. Flowers are of two types. Rotate flowers are erect, starshaped, project outward or slightly upward in orientation, and exhibit the stamens and pistil conspicuously. Campanulate flowers nod from twisted pedicels borne on an oblique rachis, hiding the stamens and pistil from view until one reorients the flower manually. Flowers are white or bear hues of anthocyanin pigments. Buds exhibit pigmented hues before opening. Pigmentation, even within cultivars, will vary in hues from year to year and within a season, thus it is difficult to interpret or quantify by standardized color charts. This trait presents problems in quantifying flower colors in cultivars.

Liriopogons produce a perianth of petals and petaloid sepals fused basally, with conspicuous free lobes above. Some plants exhibit little fusion, and the perianth appears free nearly to the base. Others exhibit a perianth with a distinct broadened, campanulate tube that occasionally narrows abruptly into a prolonged basal "perigone" that mimics the pedicel in appearance. Flowers will dehisce at the joint between the pedicel and perigone. Perianth lobes are similar in length with the free sepal lobes typically about $0.5 \mathrm{~mm}$ narrower than petal lobes. Some members exhibit a narrow rim (0.1-0.5 $\mathrm{mm}$ ) along the edge of the perianth inner lobe's surface that lacks pigmentation, making the flower's pigment appear lighter in color. The perianth is persistent during early stages of fruit development, then losing pigmentation upon drying and finally dropping.

AndROECIUM. Liriopogon androecia have six stamens that are free and extrose, but exhibit two distinct types. Some liriopogons bear zygomorphic stamens, with a conspicuous, sigmoid filament that orients the stamens to the lowest side of the flower. Filaments are pigmented like the perianth. Anthers are yellow, oblong, and dehisce only in the upper quarter of the suture, giving them the appearance of being poricidal. Other liriopogons bear actinomorphic stamens, with subsessile anthers borne in a ring around the stigma. Anthers are yellow, sagittate, and dehisce longitudinally along nearly its entire length.

Gynoecium. Liriopogon flowers contain one pistil with six lobes and one central style that may be shorter than, subequal, or longer than the stamens.

There are two distinct types. Some liriopogons have hypogynous ovaries with the style incurved-falcate, cylindrical, and bearing a diffused stigma of papillae. Other liriopogons have hemiperigynous ovaries with the style straight, tapering slightly from the base to apex, and bearing a trifid (three-lobed) stigma.

Fruit. Historically, descriptions of fruit vary and are described as a berry (Bailey, 1929), a drupe (Hume, 1961), berry-like (Huxley et al., 1992), or as a leathery capsule rupturing early to expose the seed (Cutler,(1992). Anatomical studies indicate that the pistil of liriopogons splits irregularly, but more or less transversely in the postfloral stage to expose developing seeds (Dahlgren and Clifford, 1982). The exposed seed with the testa (seedcoat) would then provide the color.

One species was emphasized as unique in bearing up to six fruit per pedicel, whereas other species typically produced one (Hume, 1961). Hume's conclusion was based on a small sample size studied. Plants in this study regularly produced one to four fruit per pedicel, or occasionally six fruit per pedicel. Many cultivars lacked fruit or were sparsely fruited. The fruit was berry-like, subglobular to ovoid fruit with a leathery wall that remained intact, not rupturing early to expose the seed. Occasionally, the fruit split irregularly to expose one seed within that occupied nearly all the space. Fruit of some liriopogons was purplish-black to black, exposing brownish seeds, or greenish-blue to blue to bluish-black exposing brownish or white seeds.

\section{Reliable characters for segregation.}

Examination of a multitude of macromorphological characters from a wide range of liriopogon germplasm in cultivation in the eastern United
States indicates that genera and species can be segregated accurately. Characters associated with reproductive structures were more reliable than those associated with vegetative structures for accurate identification. Characters of the inflorescence axis, bracts, flowers, stamens, pistil, fruit, and leaf venation appear reliable for segregation of genera. Species can be segregated by a combination of multiple vegetative and floral characters, but will require plants to be in the floral state for accurate identification. Leaf lengths must come from matured leaves late in the season.

Leaf widths can be quantified, a useful trait for cultivars and some species. Foliar bract lengths must come from the earliest-produced scapes. Peduncle lengths must come from scapes produced in early to midseason. Flower color varies in hues within and between seasons, and thus are less reliable, even in cultivars. Thus, standardized color chart values loose their value in floral descriptions. Fruit production varied somewhat between seasons, lacking in some years. Several named species survived vegetatively for more than one season, but never produced scapes. Thus, these taxa were more difficult to segregate.

\section{Number of liriopogon genera.}

There are four genera sold as liriopogons in the trade. Two genera are imposters-misidentified sedges (Cyperus L., Kyllinga Rottb., Cyperaceae Juss.). I had been informed over the years from liriopogon growers that some nurserymen in the eastern United States were unable to distinguish liriopogons from grass-like weeds, marketing the weeds as liriopogons. Twice, I was able to document this rumor. In June 1995, a discount chain in Raleigh, North Carolina, was selling Liriope exiliflora (L.H. Bailey) H.H. Hume as "an unknown landscape species that forms dense mounds of yellowish flowers." This imposter was Cyperus, bought and assigned research number 95-242, and vouchered (Fantz 5930) for deposit in a herbarium. In July 1996, a different discount chain in Clearwater, Florida, was marketing a liriopogon plant as "Liriope minor. New. Fine textured plant. Colonizes an area readily. Desired for its reduced size and miniature fruits." This 
imposter was Kyllinga, bought and assigned research number 96-246, and vouchered (Fantz 6117).

These imposters were rare, but were documented as available in garden centers and marketed as new liriopogon taxa. They bear grass-like leaves and root tuberoids or storage organs, as do liriopogons. Sedges are distinguished by their tristichate (three-ranked) leaves, peduncles triangular in cross-section, branched inflorescence rachises, and strawcolored flowers with reproductive organs hidden inside bracts.

Occasionally, one can find a pot(s) of liriopogon that bears bibs with distichous (two-ranked) leaves and lacking scapes. Leaves are pubescent and bear a distinct junction (the ligule) in the leaf between the sheath and the flat blade. These are grasses (Poaceae Barnh.), outcompeting the liriopogon bibs (individual daughter plants) that died, leaving only the grasses living in pots being marketed. Other pots bearing the same label name in garden centers were recognizable as liriopogon taxa.

Liriopogons have several characters that come in contrasting pairs or two distinct types. When segregated and correlated, these distinct types fall into two distinct groupings; hence, evidence that there are two distinct genera of liriopogons. Table 4 provides reliable characters of segregation for Liriope and Ophiopogon. Liriope taxa can be distinguished easily by the zygomorphic, rotate flowers borne on terete peduncles, sigmoid filaments bearing oblong, poricidal anthers, and a cylindrical incurved-falcate style bearing an unlobed, papillae stigma. The flowers open outward to upward, borne on straight pedicels. Ophiopogon taxa can be distinguished easily by the actinomorphic, campanulate flowers borne on a flattened peduncle, straight filaments bearing sagittate, longitudinaldehiscent anthers, and a tapered straight style bearing a three-lobed stigma. The flowers are nodding, resulting from a twisted pedicel.

\section{Vernacular or common names.}

Liriopogons cultivated in western countries lacked a vernacular or an English name (Bailey, 1929). A historical practice has been to use the generic name as a common name when a vernacular name is lacking.

Table 4. A comparison of liriopogon genera.

\begin{tabular}{lll}
\hline Character & \multicolumn{1}{c}{ Liriope } & \multicolumn{1}{c}{ Ophiopogon } \\
\hline $\begin{array}{l}\text { Peduncle type } \\
\text { Peduncle diameter } \\
\text { and width }\end{array}$ & $\begin{array}{l}\text { Terete } \\
\text { Cylindrical, consistent }\end{array}$ & $\begin{array}{l}\text { Plano } \\
\text { Tapered apex to base } \\
\text { Peduncle cross-section }\end{array}$ \\
$\begin{array}{l}\text { Flower type } \\
\text { Flower orientation }\end{array}$ & Terete & Flat \\
Pedicels & Spreading to upward & Campanulate \\
Stamens symmetry & Straight & Nodding \\
Filament length & Zygomorphic & Twisting \\
& Prominent, & Actinomorphic \\
Filament shape & anthers stalked & Inconspicuous, \\
Anther shape & Sigmoid & anther subsessile \\
Anther dehiscence & Oblong & Straight \\
Ovary position & Poricidal & Sagittate \\
Style length & Hypogynous & Longitudinal \\
Style diameter & Incurved-falcate & Hemiperigynous \\
Stigma & Cylindrical, consistent & Straight \\
& Unlobed, diffused & Tapered base to apex \\
Fruit & papillae & Three-lobed \\
Seeds & Purplish-black to black & Blue to bluish-black \\
\hline
\end{tabular}

Currently, there are five common names associated with liriopogons.

LiLYTURFs. The name "lily-turf" was coined for all liriopogons based upon their low sod-forming or turfing plants of the lily family (Bailey, 1929). The hyphen has been eliminated over time. However, modern practice has been to use the name strictly for members of Liriope. Rarely has the name been associated with Ophiopogon.

SNAKESBEARD. The generic name Ophiopogon (ophio: Greek for snakelike, and pogon: Greek for beard) was proposed by Ker-Gawl (1821). The inflorescence in many species of Ophiopogon has an obliquely arching rachis from which twisted pedicels project downward. These scapes resemble a cobra ready to strike, with the peduncle representing the snake's body, the rachis the cobra's hood and head, and the persistent pedicels the beard. An infrequently used name, presumably because Bailey reported that this name "had no significance to us" (Bailey, 1929). This vernacular name has been used strictly with Ophiopogon.

Mondo Grass. Bailey recognized his second liriopogon genus as Mondo (Bailey, 1929). Later, the generic name Ophiopogon was conserved over the generic name Mondo as the correct name for the genus (by international rules). The name "mondo grass" came into use for those grass-like plants of the genus Mondo. The name "mondo grass" has continued to be used and is applied strictly to Ophiopogon.

MoNKEY GRAss. The origin of this name is unknown. It is applied commonly to those liriopogons of both genera with narrower leaves that bear inflorescences amongst the leaves and creeps to form ground colonies. Everyone with whom I have discussed the origin of the name monkey grass learned it from other individuals using the name.

The following incident may be irrelevant, but is reported for potential insight on this name's origin. I was teaching a laboratory class on ornamental plants. The students and I were kneeling beside a massing of the mondo grass, Ophiopogon japonicus Ker-Gawl. We were spreading leaves with our hands to locate and observe the hidden cobalt-blue fruit. A homesick Asian student (Thailand) observed our actions and became emotional, exhibiting symptoms associated with suppressed crying. Our actions resembled those of monkeys in his homeland that descend from trees to the forest floor, searching patches of grassy leaves for edible berries to eat. To this Asian student, we were those monkeys!

AzTec Grass. "Aztec grass" is a name used infrequently for a group of variegated Liriope (not cold hardy) in the lower south with broader leaves 
Key to genera of cultivated liriopogons

Imposters are included in the key to assist those in their identification. True liriopogons are represented in couplet number 3 only. Table 4 provides additional characters for comparison.

1. Leaves three-ranked, sheaths closed; peduncles triangular

(nonliriopogons) Sedges

1. Leaves two-ranked, sheaths open.

2. Stamens and pistils enclosed in bracts; leaves commonly pubescent, bearing a ligule at the junction of the sheath with the blade (nonliriopogons) Grasses

2. Stamens and pistils enclosed in a petaloid perianth; leaves glabrous, lacking a ligule Liriopogons

3. Stamens zygomorphic; filament conspicuous, sigmoid (s-shaped); anthers oblong, dehiscence poricidal; style incurved-falcate, cylindrical; stigma papillate; perianth inserted below the ovary; flowers erect to spreading, rotate Liviope

3. Stamens actinomorphic; filaments inconspicuous; anthers saggittate, dehiscence longitudinal; style straight, gradually tapering to the apex; stigma trifid; perianth fused to basal portion of ovary; flowers nodding, campanulate

Ophiopogon

and elongated inflorescences. The origin of the name is unknown. All plants obtained for this research study with the vernacular name of aztec grass were Ophiopogon, not Liriope. This included the typical selections with elongate leaves and inflorescences and dwarf selections of aztec grass sold under the name Liriope.

\section{Conclusion}

One cannot rely only on names found upon plant labels as accurate identifications, as many liriopogons sold are misidentified to genus. Researchers will obtain misleading results when they rely on the names of plants obtained in the trade as an accurate source of segregation of liriopogon taxa. Results based upon misidentified research samples will lead to incorrect conclusions. There are two distinct genera of cultivated liriopogons, Liriope and Ophiopogon, in the eastern United States that can be distinguished accurately to genus when flowers are present. Occasionally, one will encounter pots labeled as a liriopogon, but these are imposters distinguished easily by the pubes- cent leaves with ligules, flowers enclosed in straw-colored bracts, or triangular scapes and leaf arrangements.

\section{Literature cited}

Adams, G. 1989. Great ground covers. Amer. Nurseryman 170(8):83-91.

Bagust, H. 1992. The gardener's dictionary of horticultural terms. Cassell Publishers, London.

Bailey, L.H. 1929. The case of Ophiopogon and Liriope. Gentes Herbarum 2(1):3-37.

Bentham, G. and J.D. Hooker. 1880 Genera plantarum. Volume III. Reeve, London.

Cutler, D.F. 1992. Vegetative anatomy of Ophiopogoneae (Convallariaceae). J. Linnean Soc. Bot. 110:385-419.

Dahlgren, R.M.T. and H.T. Clifford. 1982. The monocotyledons: A comparative study. Academic Press, London.

Dahlgren, R.M.T., H.T. Clifford, and P.F. Yeo. 1985. The families of the monocotyledons: Structure, evolution and taxonomy. Springer-Verlag, New York.
Fantz, P.R. 1993. Taxonomic problems in cultivated liriopogons. HortTechnology 3(2):146-150.

Fantz, P.R. 1994. A taxonomic research update of cultivated liriopogons. HortTechnology 4(1):46-48.

Griffiths, M. 1994. Index of garden plants. Timber Press, Portland, OR.

Harris, J.G. and M.W. Harris. 1994. Plant identification terminology: An illustrated glossary. Spring Lake Publishing, Spring Lake, UT.

Hume, H.H. 1961. The Ophiopogon-Liriope complex. Baileya 9:135-158.

Huxley A., M. Griffiths, and L. Margot (eds.). 1992. The new Royal Horticultural Society dictionary of gardening. Macmillan, London.

Ker-Gawl, J.B. 1821. Ophiopogon spicatus. blue-flowered snakesbeard. Edward's Botanical Register Table 593.

Maximowicz, C.J. 1781. Ophiopogonis species in herbariis Petropolitanis servatas exposuit. Bulletin de l'académie impériale des sciences de Saint-Pétersbourg 15:8390 .

Mcharo, M., E. Bush, D. La Bonte, C. Broussard, and L. Urbatsch. 2003. Molecular and morphological investigation of ornamental liriopogons. J. Amer. Hort. Sci. 128(4):575-577.

Mularoni, T. and C.E. Anderson. 1987. Growth of Liriope muscari in response to various temperature, photoperiod and nutrient combinations, p. 37-49. In: Phytotron report. North Carolina State University Press, Raleigh, NC.

Radford, A.E., W.C. Dickison, J.R. Massey, and C.R. Bell. 1974. Vascular plant systematics. Harper \& Row, New York.

Rudall, P.J., J.G. Conran, and M.W. Chase. 2000. Systematics of Ruscaceae/ Convallariaceae: A combined morphological and molecular investigation. J. Linnean Soc. Bot. 134:73-92.

Stevens, P.F. 2006. Angiosperm phylogeny website. Version 7. 28 May 2006. <www.mobot.org/MOBOT/research/ APweb/welcome.html>. 